\title{
Development of Nitrided Selective Wave Soldering Tool with Enhanced Lifetime for the Automotive Industry
}

\author{
Zsolt Sályi, Zsolt Veres, Péter Baumli and Márton Benke
}

\begin{abstract}
The aim of our research is to develop an economic material combination exhibiting good wetting with solder alloy melts and enhanced lifetime against erosion in lead-free soldering applications. Iron-nitrides have strong bonds compared to metals, therefore they are expected to have increased resistance against erosion in solder melts compared to iron soldering tools. The first step of our research is to find the proper substrate material for nitride coating to obtain the desired wetting behaviour. The present paper focuses on the substrate material selection through wetting examinations of nitrided W302, 42CrMo4 and C45 steels with SAC 305 solder alloy melt. It was found that the substrate composition strongly affects the wetting contact angle. The best wetting was achieved with the C45 type steel substrate. The correlation between substrate composition, compounds formed during nitriding and wetting behaviour is discussed.
\end{abstract}

\section{Introduction}

In selective soldering applications the solder alloy melt is driven to the soldering location with a soldering tool. In case of selective wave soldering, the tool is a nozzle, while for hand soldering it is the tip of the soldering iron. For all cases, the soldering tools must have good wettability with the solder alloy melt to ensure a stable contact with the component to be soldered. In most cases, the tool is

Z. Sályi $(\square) \cdot$ Z. Veres $\cdot$ P. Baumli $\cdot$ M. Benke

Institute of Physical Metallurgy, Metalforming and Nanotechnology,

University of Miskolc, Miskolc, Hungary

e-mail: zsolt.salyi92@gmail.com

Z. Veres

e-mail: vezso3838@gmail.com

P. Baumli

e-mail: peter.baumli@gmail.com

M. Benke

e-mail: fembenke@uni-miskolc.hu

K. Jármai and B. Bolló (eds.), Vehicle and Automotive Engineering,

Lecture Notes in Mechanical Engineering, DOI 10.1007/978-3-319-51189-4_18 
produced of iron with low alloying element/impurity concentration or high purity Armco iron. For those tools, the metallic type bonding in iron ensures the desired wettability with the molten solder alloy. At the Fe-solder alloy melt interface, $\mathrm{FeSn}_{2}$ intermetallic layer is formed [1]. The wettability is further enhanced through the $\mathrm{FeSn}_{2}$ intermetallic layer at the tip/solder melt interface. The FeSn $\mathrm{Fintermetallic}$ layer is either produced intentionally prior to soldering (hand soldering) or during the first soldering cycle (selective wave soldering). During application, the thickness of the intermetallic layer gradually increases with soldering cycles. Fe atoms are provided by atom transport from the tool as the $\mathrm{FeSn}_{2}$ intermetallic layer thickens. This atom extraction appears macroscopically as the erosion of the soldering tool. The erosion produces a rough surface on which ditches also form in the later stages. The erosion is further enhanced in the ditches where the solder melt is in contact with unharmed Fe surface. After a certain degree of erosion, the good wetting between tool and solder melt is destroyed and the tool must be replaced. The erosion is accelerated by the application of lead-free soldering alloys such as SAC and INNOLOT due to the increased Sn content compared to previously used $\mathrm{Sn}-\mathrm{Pb}$ alloys and the elevated soldering temperature [2-12]. The erosion process is more pronounced in selective wave soldering applications where the tool is exposed to the continuous flow of solder alloy melt [9]. In such applications, the erosion effect of the melt flow contributes to the diffusion driven Fe extraction. Finally, the degradation of the soldering tool leads to the need to replace the soldering tool which, in turn, requires the interruption of the soldering process, calibration of the new tool and cause an overall loss of production time for soldering companies.

The erosion reaction of metals in $\mathrm{Sn}$ based solder alloys can be reduced by composition modification of the solder alloy melt. Nishikawa et al. showed that Co addition to Sn-Ag solder alloy effectively reduces the erosion reaction of iron plated copper in Sn-Ag solder melt [11]. However, if the solder composition cannot be modified, the erosion reaction must be suppressed by designing erosion resistant solder tools. Watanabe et al. examined the erosion resistance of Fe-MWCNT (Multi Wall Carbon Nanotube) composite in lead free solder melt. They found that the wetting conditions decreased, but the resistance against erosion was increased [12]. Although a promising material might have been found, the fabrication of the developed composite material is quite costly and its production can only be carried out in laboratory conditions.

The long-term objective of our research is to develop an economic and commercially obtainable substrate-coating material combination that exhibit proper wetting with the most commonly used lead-free SAC solder alloys and increased erosion resistance compared to the currently applied iron tools. The first step of our research is the selection of the proper substrate material and the wetting examinations of nitride coatings. For substrates, three steel types were chosen with varying alloying contents, being W302, 42CrMo4 and C45. For coatings, Fe-nitrides were produced at the surface of the substrates with two different nitriding processes. In this manuscript, the results of wetting contact angle measurements are presented and the correlation between contact angle and substrate composition is discussed. The potential substrate-nitride combination of selective 
soldering tool applications is selected based on the results of the wetting examinations. The examination of the erosion behaviour of the potential substrate-nitride combination will be the next step of the research and is not yet performed.

\section{Materials and Methods}

Three steel types were chosen for substrates with decreasing alloying element contents being W302, 42CrMo4 and C45, respectively. The standard compositions of the examined steels are given in Table 1 .

Plates with dimensions of $8 \mathrm{~mm} \times 10 \mathrm{~mm} \times 1 \mathrm{~mm}$ were cut from the bulk alloys. The plates were austenized in an air furnace at $860{ }^{\circ} \mathrm{C}$ for $30 \mathrm{~min}$, then quenched in room temperature water. The plates were subsequently annealed at $600{ }^{\circ} \mathrm{C}$ for $20 \mathrm{~min}$ in air furnace. According to Böhler's recommendation, at least $2 \mathrm{~h}$ of annealing is required in the case of W302 steel. The annealing time was chosen to be shorter, since the subsequent nitriding ensured the completion of the annealing process. After removing the decarburized surfaces the plates were divided into two groups. The two groups were subjected to different nitriding processes. For the first group, before the nitrocarburising a preoxidation at $350{ }^{\circ} \mathrm{C}$ for $30 \mathrm{~min}$ in an air medium was carried out. Then the plates were heated up to the nitriding temperature of $550{ }^{\circ} \mathrm{C}$ in nitrogen. This heating type is the standard heating process in conventional gas nitriding that removes contaminations and produces an oxide layer on the surfaces. After $6 \mathrm{~h}$ of the nitriding, the furnace was cooled down and the samples were removed. Samples of such treatment are called here as "oxidized" For the second group, the plates were heated up to $550{ }^{\circ} \mathrm{C}$ in nitrogen atmosphere. Thus, no oxide layer was produced. After $6 \mathrm{~h}$ of nitriding the furnace cooling down and the samples were removed. Samples of this group are called as "oxide-free".

X-ray diffraction (XRD) phase analysis was performed with a $40 \mathrm{kV} 40 \mathrm{~mA}$ Bruker D8 Advance diffractometer using Co tube.

Before wetting angle measurements, the surfaces of the samples were cleaned with a commercial flux, Lux-Tools DIN EN 29454. The samples were placed in an air furnace with a small piece of SAC 305 solder alloy on the top. The composition of the SAC 305 alloy is given in (Table 2) After holding the samples at $320{ }^{\circ} \mathrm{C}$ for

Table 1 The standard compositions of the examined steels, wt $\%$

\begin{tabular}{l|l|l|l|l|l|l|l|l|l|l|l}
\hline & $\mathrm{C}$ & $\mathrm{Si}$ & $\mathrm{Mn}$ & $\mathrm{Cr}$ & $\mathrm{Mo}$ & $\mathrm{Ni}$ & $\mathrm{V}$ & $\mathrm{W}$ & $\mathrm{Co}$ & $\mathrm{P}$ & $\mathrm{S}$ \\
\hline W302 & 0.39 & 1.10 & 0.40 & 5.20 & 1.30 & - & 0.95 & - & - & - & - \\
\hline 42CrMo4 & $0.38-$ & $<0.40$ & $0.60-$ & $0.90-$ & $0.15-$ & - & - & - & - & $<0.035$ & $<0.025$ \\
& 0.45 & & 0.90 & 1.20 & 0.30 & & & & & & \\
\hline C45 & $0.42-$ & $<0.40$ & $\begin{array}{l}0.50- \\
0.80\end{array}$ & $<0.40$ & $<0.10$ & $<0.40$ & - & - & - & $<0.045$ & $<0.045$ \\
& 0.50 & & & & & & & & \\
\hline
\end{tabular}


$20 \mathrm{~min}$, they were removed and cooled down to measure the equilibrium contact angles. If the contact angles measured on the two sides of the same sample happened to deviate with $10^{\circ}$, the results were neglected. Such deviations originated from surface roughness caused by improper sample machining. The presented results are the average of contact angles measured on the two sides of the same sample.

Glow Discharge Optical Emission Spectrometry (GD-OES) examinations were carried out with a GD Profiler 2 (Power: $25 \mathrm{~W}$, Module: $6 \mathrm{~V}$, Phase: $5 \mathrm{~V}$, Pressure: $500 \mathrm{~Pa}$, flushing time: $5 \mathrm{~s}$, pre-integration time: $100 \mathrm{~s}$ ).

\section{Results}

Figure 1 shows the $\mathrm{X}$-ray diffraction patterns of the oxide-free nitride samples. Bragg reflections of $\mathrm{Fe}_{2-3} \mathrm{~N}(\varepsilon)$ and $\mathrm{Fe}_{4} \mathrm{~N}\left(\gamma^{\prime}\right)$ nitrides and the ferrite substrate can be seen. No reflections of any other phases are present. Note that Co tube was applied, which excites $\mathrm{Cr}$ atoms. Due to the fluorescence radiation originating from the excitement of the $\mathrm{Cr}$ atoms, the sign/background ratio of W302 alloy is lower

Table 2 Composition of the SAC 305 alloy used for wetting angle measurements, wt $\%$

\begin{tabular}{l|l|l}
\hline $\mathrm{Sn}$ & $\mathrm{Ag}$ & $\mathrm{Cu}$ \\
\hline 96.34 & 2.95 & 0.59 \\
\hline
\end{tabular}

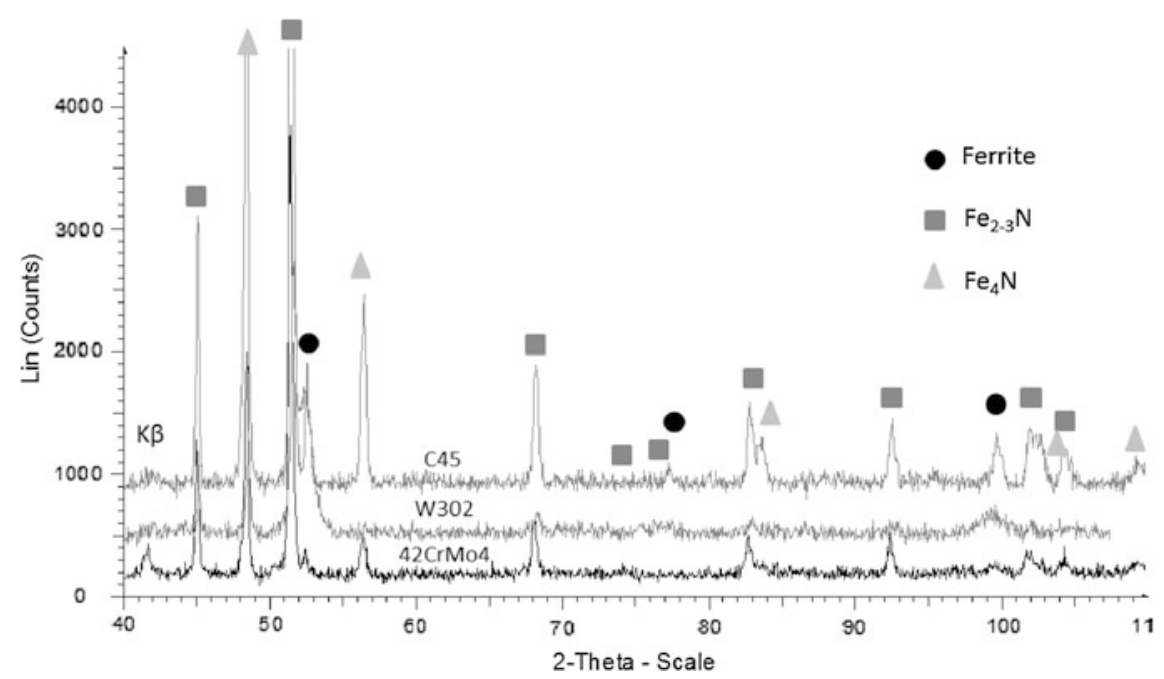

Fig. 1 XRD patterns of the oxide-free nitride coated W302, 42CrMo4 and C45 samples 


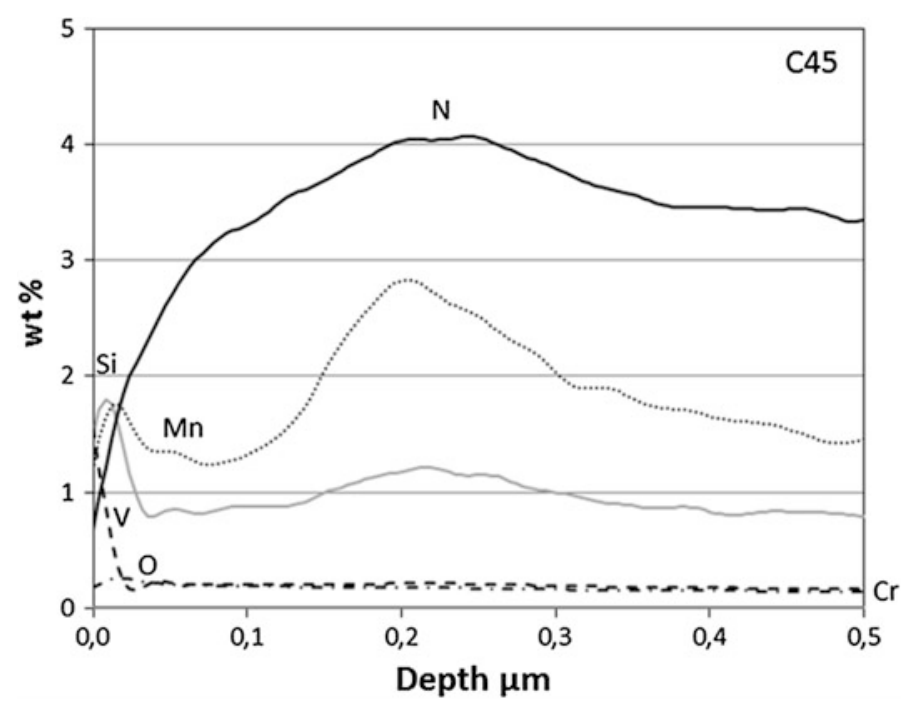

Fig. 2 GD-OES spectra of the C45 alloy with oxide-free nitride coating

compared to $42 \mathrm{CrMo} 4$ and $\mathrm{C} 45$, therefore lower intensity peaks are not visible on the spectrum of the W302 sample.

Figure 2 shows the near-surface region of GD-OES spectra of alloying elements of the C45 sample with oxide-free coating. Since the equipment was not calibrated for $\mathrm{N}$ and $\mathrm{O}$ elements, their absolute value could not be determined. However, the distributions of these elements are well represented. For other elements, both their distributions and absolute values could be determined. It can be seen that the increase of the $\mathrm{N}$ content is monotonic with increasing depth. There is a small peak of $\mathrm{O}$ in the sub-surface region, meaning that some $\mathrm{O}$ atoms were present during the nitriding process. The Si and Mn show definite peaks near the surface. The relative positions of $\mathrm{Si}, \mathrm{Mn}$ and $\mathrm{O}$ peaks indicate that compounds/complexes of $\mathrm{Si}, \mathrm{Mn}$, and $\mathrm{O}$ formed on the surface with an amount less than $2 \mathrm{wt} \%$. There is a small quantity of $\mathrm{V}$ in the alloys, which diffused from the bulk to the surface.

Figure 3 shows the near-surface variation of elements of the 42CrMo4 sample with oxide-free coating. Again, the $\mathrm{N}$ content increases monotonically with depth in the near surface region. Only a small peak appears in the Mn content with less than $1 \mathrm{wt} \%$.

Figure 4 shows the GD-OES spectra of the W302 sample with oxide-free coating. It can be seen that $\mathrm{Cr}, \mathrm{Si}, \mathrm{Mn}, \mathrm{O}$ have peaks at the same positions. Furthermore, the distribution of $\mathrm{N}$ is not monotonic, but having a local peak exactly where $\mathrm{Cr}, \mathrm{Si}, \mathrm{Mn}$ and $\mathrm{O}$. This means that compounds/complexes of $\mathrm{Cr}, \mathrm{Si}, \mathrm{Mn}, \mathrm{O}$ and $\mathrm{N}$ formed at the surface. The net amount of these compounds exceeds $5 \mathrm{wt} \%$. The $\mathrm{V}$ diffused from the bulk to the surface.

Figure 5 shows the measured equilibrium contact angles of the oxidized samples and molten SAC 305 solder alloy systems. The W302 sample has the highest 


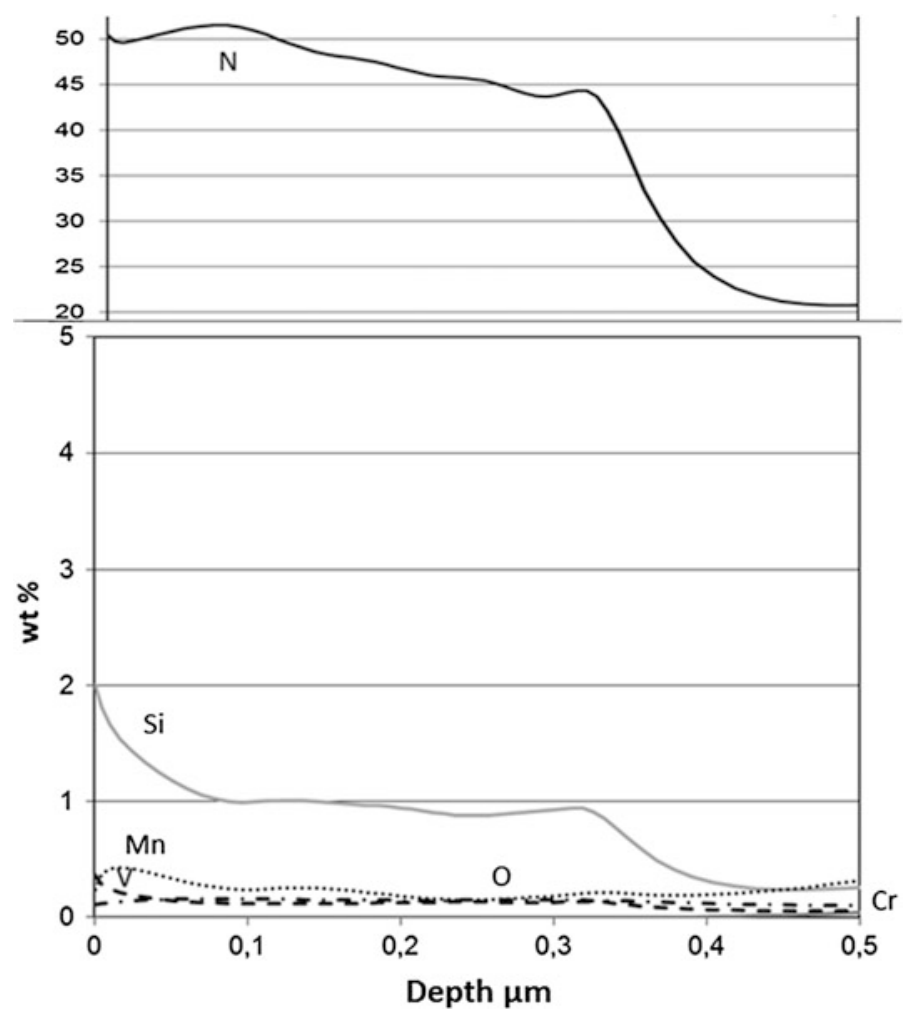

Fig. 3 GD-OES spectra of the $42 \mathrm{CrMo} 4$ alloy with oxide-free nitride coating

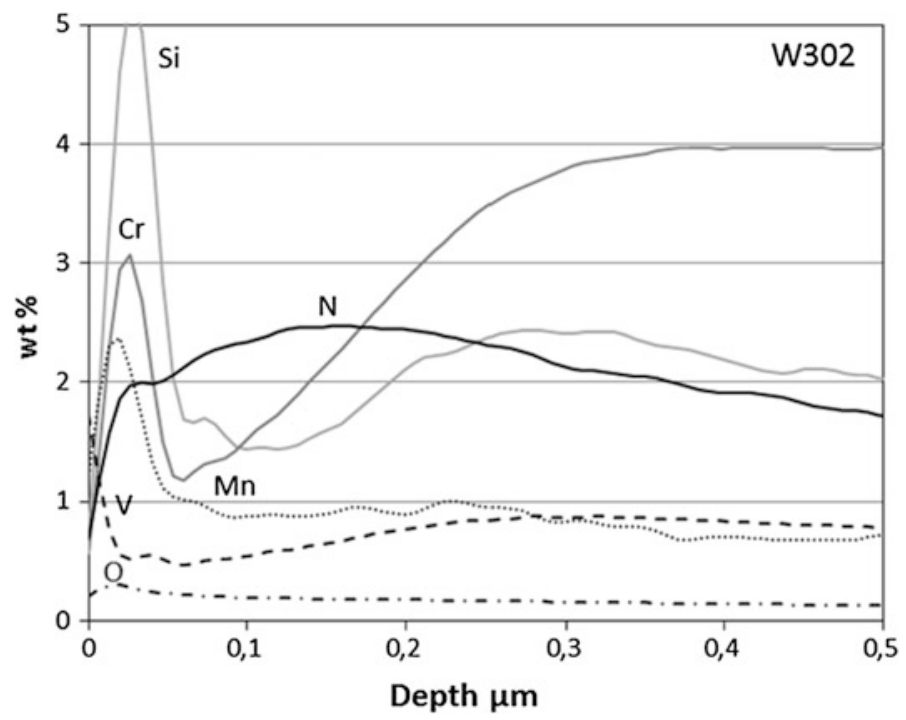

Fig. 4 GD-OES spectra of the W302 alloy with oxide-free nitride coating 


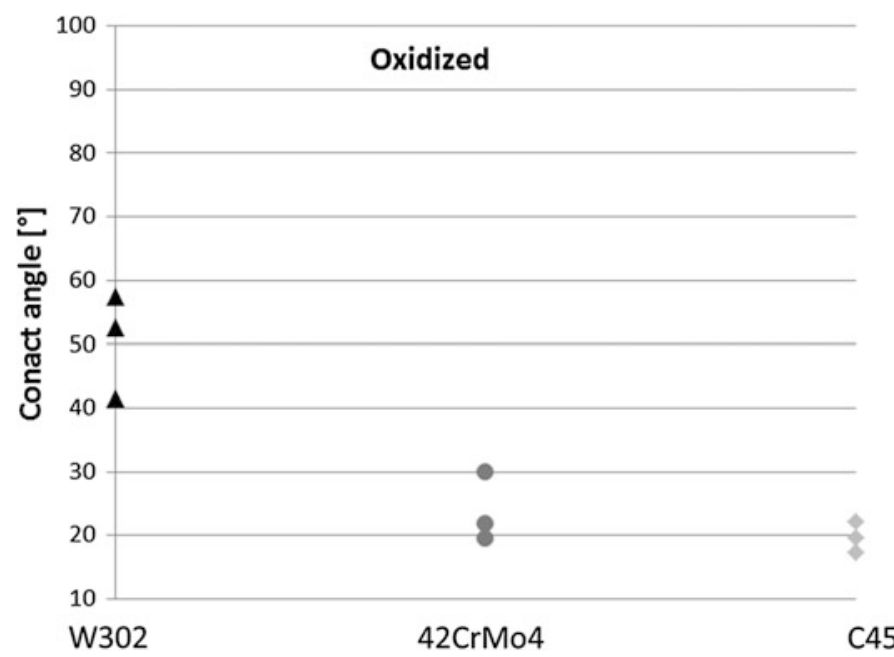

Fig. 5 Contact angles of the SAC305 alloy on the oxidized nitride coated W302, 42CrMo4 and C45 substrate

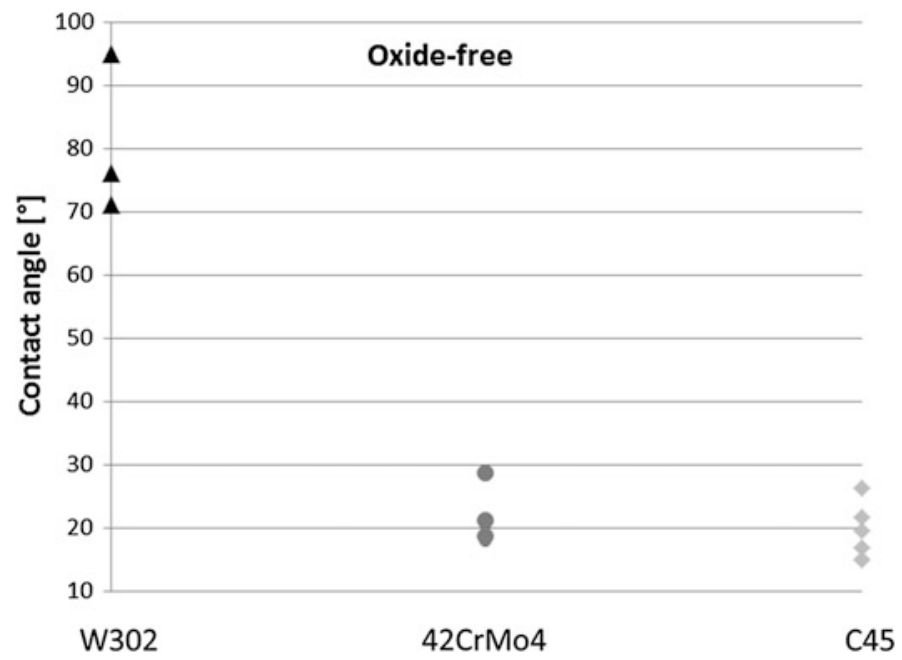

Fig. 6 Contact angles of the SAC305 alloy on the oxide-free nitride coated W302, 42CrMo4 and C45 substrate

contact angles of $\sim 40^{\circ}-50^{\circ}$, thus, it has the poorest wetting with the SAC 305 alloy. The contact angle for the $42 \mathrm{CrMo} 4$ samples are $\sim 20^{\circ}-30^{\circ}$, while those of the C45 samples are $\sim 20^{\circ}$.

Figure 6 shows the contact angles of the oxide-free samples and molten SAC 305 solder alloy systems. The contact angles for the W302 samples are $\sim 70^{\circ}-100^{\circ}$. 
As for the 42CrMo4 and C45 samples, the contact angles are the same, being $\sim 20^{\circ}$. It is worth to note that the oxide-free nitriding notably increased the wetting angles of the W302 samples compared to the oxidized nitriding. For the 42CrMo4, there is only a slight increase in contact angles, while none is for the C45 samples.

\section{Discussion}

XRD examinations confirmed that $\mathrm{Fe}_{2-3} \mathrm{~N}(\varepsilon)$ and $\mathrm{Fe}_{4} \mathrm{~N}\left(\gamma^{\prime}\right)$ nitrides were produced at the surface of the oxide-free nitrided samples. For the C45 and 42CrMo4 alloys, GD-OES examinations revealed that no notable quantity of oxides/nitrides of alloying elements or impurities formed during the oxide-free nitriding. The formation of such compounds was inhibited because of the low alloying element concentration of the $\mathrm{C} 45$ and $42 \mathrm{CrMo} 4$ steels. It was concluded that the good wetting of SAC 305 soldering alloy melt on the oxide-free nitrided C45 and 42CrMo4 samples were due to the lack of additional oxides/nitrides, i.e. the desired wetting originated from the favourable adhesion between the $\mathrm{Fe}_{2-3} \mathrm{~N}(\varepsilon)$ and $\mathrm{Fe}_{4} \mathrm{~N}\left(\gamma^{\prime}\right)$ nitrides and the SAC 305 solder alloy melt. As for the W302 alloy, high wetting angles were measured after the oxidized nitriding, furthermore, wetting angles were even higher after the oxide-free nitriding. According to GD-OES examinations, nitrides of alloying elements such as $\mathrm{Cr}, \mathrm{Si}$ and $\mathrm{Mn}$ formed during the oxide-free nitriding at the surface of the W302 alloy. It is well known that $\mathrm{CrN}$ is non-wettable for most metal melts, and, because of this character, it is used as non-wetting coating in soldering and aluminum casting processes [13-15]. It was deduced that the poor wetting of molten SAC 305 alloy on the nitrided W302 alloy was due to the presence of non-wetting compounds on the surface during nitriding. Finally, the obtained results showed that low alloyed steel substrates such as $\mathrm{C} 45$ or $42 \mathrm{CrMo} 4$ with nitride coatings can be candidates for wetting coatings within lead-free soldering applications.

\section{Conclusions}

The suitability of steel substrate-nitride coating combinations as wettable materials with enhanced erosion resistance for lead-free soldering applications are being investigated. This paper reports about the correlation between substrate composition and wetting behaviour. Samples of W302, 42CrMo4 and C45 steels were covered with $\mathrm{Fe}_{2-3} \mathrm{~N}(\varepsilon)$ and $\mathrm{Fe}_{4} \mathrm{~N}\left(\gamma^{\prime}\right)$ nitride layers using gas-nitriding. For the first set of alloys, conventional oxidizing was performed prior to nitriding, while for the second sets, the oxidizing step was skipped. The wettability was examined in the pre-oxidized and oxide-free samples/SAC 305 solder alloy systems. It was found that the composition of substrates strongly affects the wettability through formation of nitrides and oxides of alloying elements at the surface. The best wetting with contact angles of $\sim 20^{\circ}$ was achieved with the C45 type steel substrate. It was 
deduced that low alloyed steel substrates with nitride coatings can be candidates for wettable materials for lead-free soldering tools.

Acknowledgements The authors are grateful for Tibor Kulcsar for the GD-OES examinations. The described article was carried out as part of the EFOP-3.6.1-16-00011 "Younger and Renewing University-Innovative Knowledge City-institutional development of the University of Miskolc aiming at intelligent specialisation" project implemented in the framework of the Szechenyi 2020 program. The realization of this project is supported by the European Union, co-financed by the European Social Fund. Marton Benke was further supported by the Postdoctral Researcher Fellowship of the Hungarian Academy of Sciences and Peter Baumli by the Janos Bolyai Research Fellowship of the Hungarian Academy of Sciences.

\section{References}

1. Nishikawa H, Takemoto T, Kifune K, Uetani T, Sekimori N (2004) Effect of iron plating conditions on reaction in molten lead-free solder. Mater Trans 45(3):741-746. doi:10.2320/ matertrans.45.741

2. Information on http://www.elexp.com/Images/Weller_Coping_with_Lead_Free.pdf

3. Shangguan D (2005) Lead-free solder interconnect reliability. ASM International. ISBN:978-0-87170-816-8

4. Henshall G, Bath J, Handwerker CA (2011) Lead-free solder process development. Wiley. ISBN:978-0-470-41074-5

5. Ipser H (2007) European cost action 531: basic research on lead-free soldering. J Mining Metallurgy 43B(2):109-112. doi:10.2298/JMMB0702109I

6. Kroupa A, Dinsdale AT, Watson A, Vrestal J, Zemanova A (2007) COST531 Project—study of the advanced materials for lead-free soldering. J Mining Metallurgy 43B(2):113-123. doi:10.2298/JMMB0702113K

7. Kroupa A, Dinsdale A, Watson A, Vřeštál JJ, Zemanova A, Broz P (2012) The thermodynamic database cost MP0602 for materials for high-temperature lead-free soldering. J Mining Metallurgy 48(3)B:339-346. doi:10.2298/JMMB120711043K

8. Takemoto T, Uetani T, Yamazaki M (2004) Dissolution rates of iron plating on soldering iron tips in molten lead-free solders. Soldering Surface Mount Technol 16(3):9-15. doi:10.1108/ 09540910410562473

9. Nishikawa H, Kang S, Takemoto T (2009) Erosion behavior and interfacial reaction of stainless steels in molten lead-free solder. Trans JWRI 38(2):53-56

10. Information on http://www.circuitspecialists.com/blog/soldering-tip-care-tips

11. Nishikawa H, Komatsu A, Takemoto T (2005) Interfacial reaction between $\mathrm{Sn}-\mathrm{Ag}-\mathrm{Co}$ solder and metals. Mater Trans 46:2394-2399. doi:10.2320/matertrans.46.2394

12. Watanabe J, Sekimori N, Hatsuzawa K, Uetani T, Shohji I (2010) Study on erosion resistance characteristics of Fe-MWCNT composite plating with respect to lead-free solder. J Phys: Conf Ser 379(012025):1-10. doi:10.1088/1742-6596/379/1/012025

13. Wang Y (1997) A study of PVD coatings and die materials for extended die-casting die life. Surf Coat Technol 94-95:60-63. doi:10.1016/S0257-8972(97)00476-3

14. Gulizia S, Jahedi MZ, Doyle ED (2001) Performance evaluation of PVD coatings for high pressure die casting. Surf Coat Technol 140:200-205. doi:10.1016/S0257-8972(01)01037-4

15. Panjan P, Cekada M, Kirn R, Sokovic M (2004) Improvement of die-casting tools with duplex treatment. Surf Coat Technol 180-181:561-565. doi:10.1016/j.surfcoat.2003.10.119 